\title{
The Origin of the Plant Diversity and the Origin of Human Races
}

\author{
Maria Kuman* \\ Holistic Research Institute, USA \\ *Corresponding author: Maria Kuman, Holistic Research Institute, Knoxville, USA \\ To Cite This Article: Maria Kuman. The Origin of the Plant Diversity and the Origin of Human Races. Am J Biomed Sci \& Res. 2019 - 4(3). AJBSR. \\ MS.ID.000782. DOI: 10.34297/AJBSR.2019.04.000782
}

Received: : July 01, 2019 | Published: July 25, 2019

\begin{abstract}
The article offers a parallel between the unlimited possibilities of plants to adapt and the unlimited possibilities of humans to adapt. While in the Darwin's evolutional theory, proclaimed in 1859, external influences modify the material body, for Goethe (in 1790) the external influences modify the archetypal form called plants' spirit. For Goethe, the whole diversity of plants is a result of adapting of this initially created archetypal form, called plant Spirit, to different environmental conditions - adapting the plant's spirit was taking many different forms. I think this was a genius intuitive insight of Goethe, but as all intuitive insights it was too much ahead of his time to be appreciated. It seems that the humans' unlimited ability to adapt to different environments has the same origin - it is done through the initially created archetypal form, called human Spirit, which is nonlinear electromagnetic field (NEMF). The quantum origin of this NEMF is the basis of the human extremely flexible adaptation, which is the foundation of the origin of races. The racial features developed as adaptation to the different climatic conditions at different geographical latitudes. However, the unlimited ability of humans to adapt could only be explained if it was done through the quantum features of his NEMF, called human Spirit.
\end{abstract}

Keywords: Origin of plants' diversity; Origin of races; Plants' initially created archetypal form; Plants' NEMF; Human's initially created archetypal form; Human's NEMF

\section{Goethe's Concept on the Origin of Plants' Metamorphoses}

We know that Goethe was a famous German writer, but the fact that Goethe wrote a book on plant metamorphoses remains unknown. Goethe wrote a book On the Metamorphosis of Plants, which was published in 1790. This was 70 years before Darwin. In this book, Goethe asked: "If all plants were not modeled in one pattern, how could I recognize that they are plants?" [1]. According to Goethe, all the variety of plants we enjoy now evolved from a single prototype of plant when adapting to different environmental conditions. In the process of adaptation new forms of plants were developed, and Goethe defined 3 major cycles of expansion and contraction in each evolution.

a. The expansion of foliage was followed by contraction into calyx and tracts.

b. The expansion of the petals of the corolla was followed by contraction into stamen and stigma and

c. The expansion into fruit was followed by contraction into seed. When these 3 cycles of expansions and contractions were completed, the plant was ready to start all over again, but in a slightly modified form. Goethe explained: "Each contraction is withdrawing in order that a higher manifestation of the Spirit may take place" [1].

Thus, while in the Darwin's evolution theory, proclaimed in 1859, external influences modify the organism, for Goethe the external influences modify the archetypal form called plants' spirit. When adapting to different environments, the plant's spirit was taking many different forms [1]. Goethe's regular publisher refused to publish his manuscript on plants telling him that he was a literary man, not a scientist. When the book got finally published in 1790 elsewhere, his manuscript On the Metamorphosis of Plants was completely ignored for 18 years. It took 30 more years before some attention was paid to Goethe's concept [1], but we are still not where Goethe was 230 years ago. This was because Goethe's way of thinking was very much ahead of his time. Goethe published his book 70 years before the Darwin's evolution theory, which spoke of material changes. Goethe spoke of Spirit changes, which we know now to be nonlinear electromagnetic field (NEMF) [2].

Goethe labeled the tendency of plants to grow up toward the Sun as male. (In ancient Tao texts the growth toward the Sun is Yang 
and Yang is male). Goethe labeled the tendency of the plant to grow earthward toward the darkness and moist of the soil as female. (In ancient Tao texts the growth toward the Earth is Yin and Yin is female - the Earth itself was always considered female - Mother Earth) [1]. The Greek philosopher (Aristotle (384 - 322 B.C.) claimed that in each animal or plant beside the bones, the blood, the nerves, the brain, the flash, there should be an etheric form, which he called Soul, but it was later specified as Spirit [1]. Soul is the unity of body and Spirit. The British physicist Sir Oliver Lodge (1851940) was convinced that "a whole world lays beyond the physical" and he joined the London Society of Psychic Research to widen his horizon on the non-physical. However, what was non-physical in his time now is the new branch of physics - nonlinear physics, which is capable of explaining the nonlinear electromagnetic field (NEMF) of living humans, animal, plants and even not alive matter [3].

I measured with my patented supersensitive electronic equipment this weak nonlinear electromagnetic field for almost 40 years. This weak NEMF rules and regulates everything in the body from the Subconscious, to which all organs are subordinated. It is done by a Quantum Computer, which operates with the waves of this NEMF, and from the Subconscious rules and regulates everything in the body. Our Mind and emotions are parts of it [4-6].

\section{The Human Races - Genetic Manipulation or Adaptation?}

If all plants originated from one prototype of plant endowed with unlimited ability to adapt and by adapting to different environmental conditions evolved into myriad of different plants, a natural question arises: How did the human races on the planet earth appear? Did the humans evolved into different racial prototypes when adapting to the different climates of planet Earth, just like the plants did? Can I provide a proof for it? Yes, I can.

Three Italian genetic specialists were paid by UNESCO for 17 years to travel all over the planet, study the human genes, and map them. They did and they publish their results in the book History and Geography of the Human Genes [7]. Since the dark-skin Africans have the same features (dark skin and small-curls hair) as the Australian aborigines, they assumed they would find common genes regardless how far Australia was from Africa.

However, their genetic studies [7] did not find any common genes between the Africans and the Australian aborigines - none, whatsoever. They publish their results without a commentary. However, since they both live at the same geographic latitude, obviously when adapting to the hot climate of this geographic latitude, they developed the same features - dark skin and small curls hair. The Ethiopians of East Africa have the same dark skin and small curls hair as the Australians and the West Africans because they live at the same latitude with hot climate. However, the Ethiopian facial features are different from the West Africans because Ethiopian ancient texts say that one of their tribes, Oromo, came from the Pacific. But since they lived at this latitude with hot climate for many thousands of years, they developed the same features - dark skin and small curls hair.
Let us take as an example the Mongoloid race. The Eskimo, who live far to the north, have the same slanted eyes as the Mongoloid race. Probably, the slanted eyes were developed as adaptation to the strong reflection of the sun light from the snow. With time, some of them moved south to present day Mongolia, China, Korea, Japan, but the slanted eyes stayed with them. Let us take as an example the white race. They lived at latitudes between the northern Eskimo and the southern black race. And when adapting to their environment with less sun and cold winters, they developed the features that are specific for them - white skin and narrow nostrils to decrease the flow of cold air. Thus, I truly believe that there was one prototype of humans on Earth at the beginning. The different races developed when adapting to the different climate of the different geographic latitudes and we have genetic studies that proved it [7]. Considering this, racial discrimination does not make any sense because we are the same people. If some of us look different, it is because their ancestors lived at different geographic latitude for thousands of years and adapting to these conditions, they developed different features.

\section{Conclusion}

If I intended to write an article about the origin of races, why did I start with the origin of plants? How does Goethe's concept relate to the origin of races? Can we merge the concept of Goethe about evolution of plants to the evolution of the Human Races? I started with Goethe's concept for the origin of plants because I believe I can apply the concept to the origin of races. The Italian genetic specialists studied the DNA, but Russian scientists found that DNA emits photons and is influenced by photons [8]. If the adaptation is done not by direct modification of DNA, but through the NEMF (called Spirit), the quantum relation to the environment would allow much more sensitive and flexible feedback connection, which would explain our unlimited ability to adapt [9]. Obviously, the photons, which influence DNA are part of our weak NEMF, which rules and regulates everything in the body. This weak NEMF (which Goethe called Spirit), being very sensitive to changes in the environment, is the basis of our unlimited possibility to adapt.

\section{References}

1. P Thompkins, C Bird (2002) The Secret Life of the Plants, Perenial, Harper.

2. M Kuman (2018) Why It Is So Important to Avoid the Acupuncture Points during Surgery - Phantom Pain and Phantom Leaf Have the Same Holographic Nature as the Subconscious Images. Chronicle of Medicine and Surgery 2(6): 265-268.

3. M Kuman (2019) How the Material World Was Created? Origin of Its NEMF. Open Access Journal of Mathematics and Theoretical Physics 2(2): $34-38$

4. M Kuman (2018) Holographic Quantum Way of Seeing, Hearing, Smelling, Memorizing and How to Use Them for Diagnosis. Research in Medical and Engineering Sciences 5(3).

5. M Kuman (2018) Measuring the Role of Way of Thinking. Chronicle of Medicine and Surgery 2(1): 94-98.

6. M Kuman (2018) The Quantum Computer in the Subconscious - a New Dimension. International Journal of Complementary and Alternative Medicine 11(4): 195-196. 
7. LL Cavalli Sforza, P Menozi, A Piazza (1994) History and Geography of the Human Genes, Princeton University Press.

8. P Garyaev (1994) Quantum Genom. Moscow, Russia.
9. M Kuman (2018) Our Unlimited Ability to Adapt. SO Journal of Immunology 6(2). 